
Not for reproduction, distribution or commercial use.

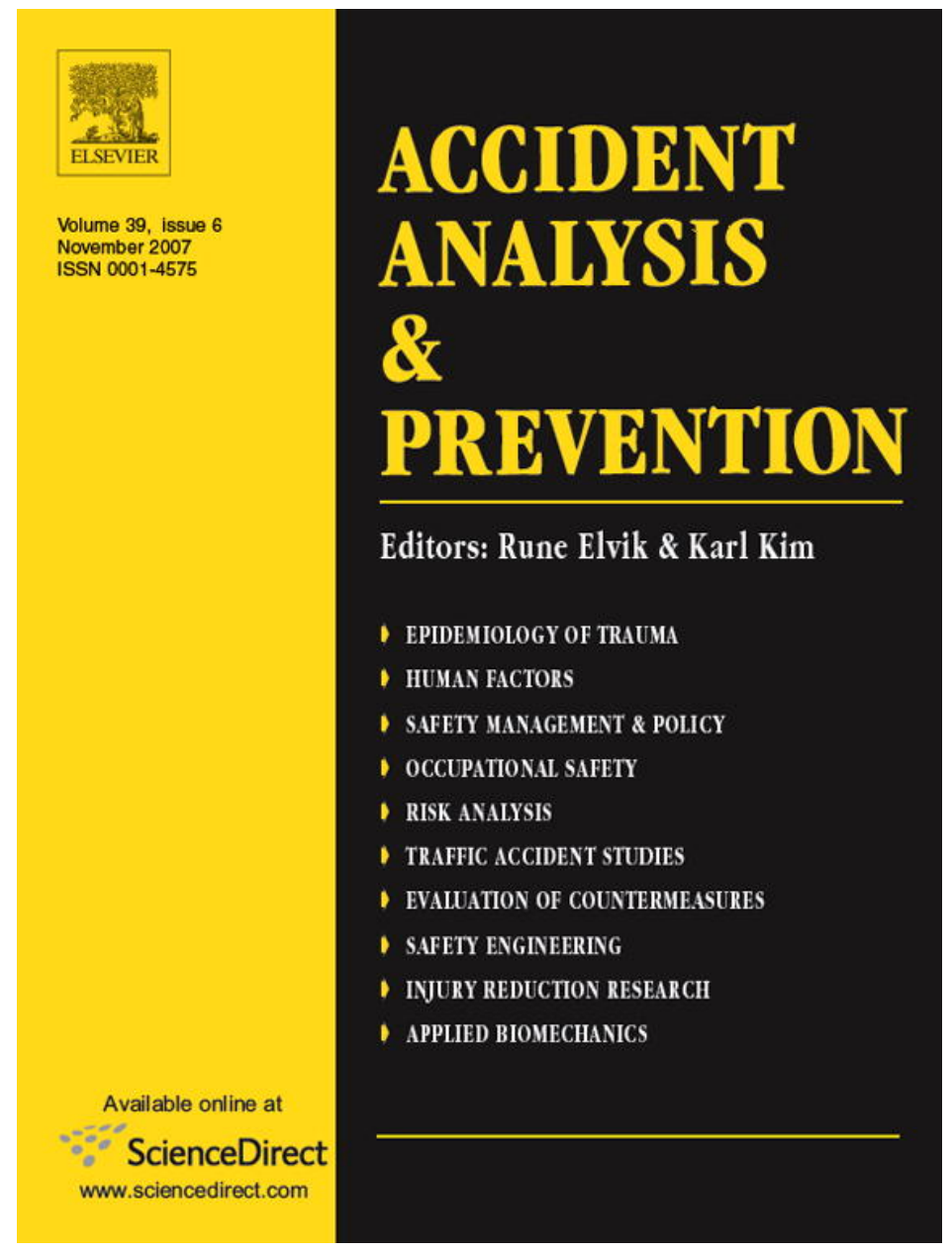

This article was published in an Elsevier journal. The attached copy

is furnished to the author for non-commercial research and education use, including for instruction at the author's institution, sharing with colleagues and providing to institution administration.

Other uses, including reproduction and distribution, or selling or licensing copies, or posting to personal, institutional or third party websites are prohibited.

In most cases authors are permitted to post their version of the article (e.g. in Word or Tex form) to their personal website or institutional repository. Authors requiring further information regarding Elsevier's archiving and manuscript policies are encouraged to visit: 


\title{
Attitudes of commercial motor vehicle drivers towards safety belts
}

\author{
Karl Kim, Eric Y. Yamashita* \\ University of Hawaii at Manoa, Department of Urban and Regional Planning, Saunders Hall 107, 2424 Maile Way, \\ Honolulu, HI 96822, USA
}

Received 9 September 2006; received in revised form 8 February 2007; accepted 19 February 2007

\begin{abstract}
Despite the fact that Hawaii has one of the highest seat belt use rates for passenger vehicles in the United States, and has had a mandatory seat belt use law since the 1980s, studies have shown that commercial motor vehicles (CMV) seat belt use rates are low. To better understand this phenomenon, a comprehensive survey of commercial vehicle drivers was conducted in Hawaii to ascertain attitudes and self-reported behaviors regarding seat belt use. A total of 791 drivers responded to a written questionnaire implemented at weigh stations and distributed to various trucking firms and transport centers. Approximately 67\% reported that they use seat belts "always" when driving a CMV (commercial motor vehicle), yet when asked how often do other CMV drivers use seat belts, only $31 \%$ responded "always." Interestingly, $86 \%$ of these same drivers reported that they use seat belts "always" when driving a personal vehicle. The major reason cited for non-use of belts was "frequent stops/inconvenience" (29\%), and "not safety conscious" (23\%). Notably, the self-reported use of safety belts is highest among operators of vans ( $88 \%$ said "always"), followed by buses ( $87 \%$ said "always") and lowest among truck drivers (only $60 \%$ said "always"). In this paper, some of the differences between self-reported users and non-users are explored and a multivariate logit model was developed to predict the odds of belt use as a function of various factors.
\end{abstract}

Published by Elsevier Ltd.

Keywords: Seat belts; Self-reported; Commercial motor vehicle (CMV); Hawaii; Logit

\section{Introduction}

In spite of the fact that Hawaii has had a mandatory seat belt use law since the mid-1980s and has achieved one of the highest rates of passenger vehicle seat belt use in the nation, observational studies indicate that the use of belts by commercial motor vehicle (CMV) operators lags behind that of passenger vehicles (Kim and Tremblay, 2005). The low use rate among CMV drivers compared to other motorists in the nation has also been confirmed by national studies, which found a use rate among CMV operators in 2003 of approximately $48 \%$ (Knoblauch et al., 2003). This seems odd, in that the benefits of belt use have been well established, particularly for large vehicle operators who seem especially vulnerable to injury and death resulting from rollover crashes (FMCSA, 2005).

The research in this paper is motivated by three underlying questions. First what is the self-reported use of seat belts by CMV drivers? Second, how does self-reported belt use vary by

\footnotetext{
* Corresponding author. Tel.: +1 808956 7381; fax: +1 8089566870 .

E-mail address: ericyama@hawaii.edu (E.Y. Yamashita).
}

different attributes of drivers, vehicles, and other factors? Third, what kinds of interventions for increasing seat belt use present themselves as a result of the attitudes and self-reported behaviors demonstrated in this study?

While Hawaii conjures images of swaying palms and white sandy beaches, it is also an ideal environment for conducting research on traffic safety. Isolated from other land masses, it is possible to not only gather valuable information on targeted groups (such as CMV drivers) it is also quite feasible to design and implement and evaluate safety interventions with the full cooperation and coordination of law enforcement and safety planners. With only four counties and one state government comprising the entire state-local sector, information and data are much more centralized than in other places.

After a brief discussion of the data and methods, and the survey instrument, the findings are presented. Then, a logit model explaining the relationships between self-reported seat belt use and various background variables and factors was developed. Following a discussion of the results, suggestions for increasing seat belt use are described as are further directions for research and analysis. 


\section{Data and methods}

The data used in this analysis come from a two-page questionnaire that was developed and implemented in the Spring of 2005. Working with traffic safety personnel in the State of Hawaii and the Office of the Federal Motor Carrier Safety Administration, a series of questions were developed to ascertain basic attitudes towards seat belt use as well as background information on driver demographics and other factors that were hypothesized to be related to restraint use among CMV drivers. The survey instrument contained questions about the frequency of seat belt use, reasons why CMV operators do not use seat belts, and ideas about what would increase seat belt use among CMV operators. In addition, questions such as the number of years driving a $\mathrm{CMV}$, the number of accidents, number of stops, gender, age, as well as other details regarding the vehicle and type of restraint system (shoulder-harness versus lap belt only) were included. The survey was then conducted statewide. A total of 1000 questionnaires were printed. There were a total of 791 completed questionnaires which were used in the analysis, translating into approximately a $79.1 \%$ response rate. A weighting method was used to sample the population of CMV drivers in Hawaii. This method was adjusted such that the islands and locations with a larger percentage of licensed CMV drivers received a greater weight. The underlying principle was to sample proportionate to the population.

The survey was conducted over a one month period at weigh stations and at various transportation and trucking companies. It was implemented by the State of Hawaii, Department of Transportation, Motor Carrier Safety staff. Several factors contribute to the high response rate. In addition to assuring respondents that their answers would be anonymous, a small token (a lanyard) was given to those who completed the questionnaire. The Motor Carrier Safety staff was extremely diligent about distributing the questionnaire and collecting it within a short time period. The instrument was designed and tested and refined so that it could be completed in less than $10 \mathrm{~min}$. Many suggested questions and topics were dropped from the instrument in order to keep it short and easy to complete. A color-coded, pre-numbered system also helped to track which island and which type of vehicle operator (truck or bus) was being surveyed.

Upon receiving the completed questionnaires, a coding scheme was developed and each questionnaire was reviewed and coded and then entered into a computerized database for cleaning and standardizing the responses. Then, using SAS, statistical analysis package, various statistical procedures, models, and reports were generated for analysis and discussion. In addition to the customary univariate and bivariate statistical procedures, a logit model was developed which was used to explain the probability of self-reported seat belt use $(\operatorname{Pr}(\mathrm{SB}))$ as a function of various driver $(D)$, vehicle $(V)$, and other $(O)$ factors:

$\left.\log _{\mathrm{e}}\left\{\frac{\operatorname{Pr}(\mathrm{SB})}{[\operatorname{Pr}(1-\mathrm{SB})}=f(D, V, O, \ldots)\right]\right\}$

This technique which has been used extensively by these researchers (Kim and Li, 1996; Kim and Yamashita, 2001) provides a method for understanding the multivariate interre- lationships between variables related to seat belt use and is described more fully in standard texts (Feinberg, 1980; Agresti, 1990).

\section{Findings and results}

In this section, the general results from the survey are described. Some of the differences between self-reported users and non-users of safety belts are detailed. A copy of the questionnaire, listing the overall frequencies and percentage distributions is contained in Appendix 1.

\subsection{General characteristics of respondents}

The ages of the respondents ranged between 18 and 75, with a mean of 42.8 and standard deviation of 10.9. Most of the respondents (approximately 72.4\%) who provided an age $(546 / 754)$ were under the age of 50 . Only 2 were under 21 and 7 were over the age of 70 . The largest age cohort was those between the ages of 40-49 years, followed by those aged 30-39. The vast majority of respondents, approximately $90 \%$ were males. In terms of driving experience, the mean years of driving were 13.9 with a standard deviation of 10.1 years. Only 5\% reported driving for less than one year, 20\% reported just less than 5 years, $20 \%$ reported just less than 10 years, $17 \%$ just less than 15 years, and $16 \%$ just less than 20 years. After 20 years, the number of drivers begins to drop off. Only $3 \%$ report that they have been driving just less than 30 years. The mean miles driven per week were 517 miles with a standard deviation of 1996. Out of the 791 responses, $508(64.2 \%)$ were drivers of trucks, $154(19.5 \%)$ were bus drivers and 92 $(11.6 \%)$ drivers of other vehicles (mainly vans). The buses included public buses, tour buses, and school buses. The majority of respondents $(64 \%)$ reported not having been involved in an accident as a CMV driver, while $19 \%$ reported having one accident and $9 \%$ stated that they had two accidents, while 5\% reported having three accidents, with $4 \%$ reporting four or more accidents.

\subsection{Self-reported seat belt use}

Of the 791 respondents, the majority, 67\%, reported that they use a seat belt "always" when driving a CMV. Fourteen percent responded that they use a seat belt "usually" while $7 \%$ claimed to use a belt "about half of the time." Eight percent said that they "rarely" use seat belts and 3\% said "never" when driving a CMV.

When asked about other CMV drivers, a different picture emerges. Asked in this manner, only $31 \%$ of the CMV drivers believed that others use belts "always." Thirty-three percent responded that other CMV drivers use belts "usually" with $18 \%$ responding that other driver use belts "about half the time." Approximately $18 \%$ of the respondents believed that other CMV drivers used belts "rarely" or "never."

When asked the question, "how often do you use seat belts when you drive a personal vehicle?" $86 \%$ of the respondents said, "always" and another $8 \%$ said "usually." Only $2 \%$ claimed 
Table 1

Those who always use seat belts

\begin{tabular}{|c|c|c|c|c|c|c|}
\hline & \multicolumn{6}{|c|}{ Always use } \\
\hline & Freq. & Pct. & Diff. in prop. & Weighted avg. & S.E. & $Z$ \\
\hline \multicolumn{7}{|l|}{ Gender } \\
\hline Female & 64 & 87.67 & 0.2312 & 0.6744 & 0.062619 & 3.692163 \\
\hline Male & 448 & 64.55 & & & & \\
\hline \multicolumn{7}{|l|}{ Age $($ mean $=42.75)$} \\
\hline Above the mean & 280 & 72.73 & 0.1225 & 0.6693951 & 0.040891 & 2.995772 \\
\hline Below the mean & 251 & 60.48 & & & & \\
\hline \multicolumn{7}{|l|}{ Vehicle type } \\
\hline Truck & 304 & 59.84 & -1.1441 & 0.69486203 & 0.090385 & -12.6581 \\
\hline Bus & 134 & 86.45 & & & & \\
\hline Van & 36 & 87.8 & & & & \\
\hline \multicolumn{7}{|l|}{ Belt use in private vehicles? } \\
\hline Always use & 500 & 73.21 & 0.4671 & 0.70483051 & 0.084423 & 5.532869 \\
\hline Don't always use & 31 & 26.5 & & & & \\
\hline \multicolumn{7}{|c|}{ Are CMVs safer than private vehicles? } \\
\hline Yes & 248 & 64.25 & 0.033 & 0.63573077 & 0.06747 & 0.489108 \\
\hline No & 64 & 60.95 & & & & \\
\hline \multicolumn{7}{|l|}{ Stops per hour } \\
\hline Less than 1 per hour & 19 & 73.08 & -1.314 & 0.67143261 & 0.126256 & -10.4074 \\
\hline 1-2 stops per hour & 127 & 72.57 & & & & \\
\hline $3-4$ & 138 & 70.41 & & & & \\
\hline $5+$ & 222 & 61.5 & & & & \\
\hline \multicolumn{7}{|l|}{ Seat belt law apply to CMVs? } \\
\hline Yes & 475 & 73.64 & 0.5599 & 0.7294158 & 0.182511 & 3.067761 \\
\hline No & 6 & 17.65 & & & & \\
\hline \multicolumn{7}{|l|}{ How much encouragement? } \\
\hline None & 84 & 53.5 & -1.4666 & 0.68493548 & 0.093858 & -15.6258 \\
\hline Periodic & 154 & 63.9 & & & & \\
\hline $1-2$ times & 56 & 55.45 & & & & \\
\hline Constant encouragement & 219 & 80.81 & & & & \\
\hline \multicolumn{7}{|c|}{ Years driving CMV? $($ mean $=13.9)$} \\
\hline Above the mean & 224 & 64.18 & -0.0389 & 0.66429021 & 0.041497 & -0.93742 \\
\hline Below the mean & 307 & 68.07 & & & & \\
\hline \multicolumn{7}{|c|}{ Miles driven per week in CMV? $($ mean $=517.25)$} \\
\hline Above the mean & 97 & 61.39 & -0.0621 & 0.66465593 & 0.053023 & -1.1712 \\
\hline Below the mean & 434 & 67.6 & & & & \\
\hline \multicolumn{7}{|c|}{ Number of accidents in CMV? $($ mean $=0.79)$} \\
\hline Above the mean & 161 & 61.22 & -0.0768 & 0.66571412 & 0.044539 & -1.72435 \\
\hline Below the mean & 370 & 68.9 & & & & \\
\hline
\end{tabular}

to use a seat belt "about half the time" and 3\% claimed to "rarely" or "never" use belts in their personal vehicles.

\subsection{Reason for seat belt non-use}

When asked for reasons why CMV drivers do not use seat belts, the leading reason given by respondents (29\%) was "frequent stops/inconvenience" followed by "not safety conscious (23\%). Other cited reasons include "discomfort" (12\%), "no/faulty seat belt" (6\%), "feel safe in big vehicle" (5\%). A large proportion, $12 \%$, "didn't know."

When asked why some CMV drivers don't buckle up in their CMVs but do use seat belts, in their personal vehicles, the leading response was that drivers "feel safe in a big vehicle" (15\%), followed by "frequent stops" (14\%), "more police enforcement of seat belt use in personal vehicles" (14\%), and "not safety conscious" (12\%). Other explanations included, "discomfort" $(6 \%)$, and no/faulty seat belt (4\%).

Interestingly, when asked "do you feel safer on the road in your CMV than in your personal vehicle, $49 \%$ said "yes," $13 \%$ said "no" and $38 \%$ said "does not make a difference." The major reason given by $67 \%$ of the respondents is "larger vehicle size" followed by "visibility" (12\%).

\subsection{How to increase belt use}

According to a NHTSA study conducted in 1998, less than one-half of drivers who drove on the job believed their company 
Table 2

And those who don't always use seat belts

\begin{tabular}{|c|c|c|c|c|c|c|}
\hline & \multicolumn{6}{|c|}{ Don't always use } \\
\hline & Freq. & Pct. & Diff. in prop & Weighted avg. & S.E. & $Z$ \\
\hline \multicolumn{7}{|l|}{ Gender } \\
\hline Female & 9 & 12.33 & -0.2312 & 0.34634 & 0.1614762 & -1.43179 \\
\hline Male & 246 & 35.45 & & & & \\
\hline \multicolumn{7}{|l|}{ Age $($ mean $=42.75)$} \\
\hline Above the mean & 105 & 27.27 & -0.1225 & 0.347384015 & 0.0595105 & -2.05846 \\
\hline Below the mean & 164 & 39.52 & & & & \\
\hline \multicolumn{7}{|l|}{ Vehicle type } \\
\hline Truck & 204 & 40.16 & 0.1441 & 0.371225652 & 0.2427813 & 0.593538 \\
\hline Bus & 21 & 13.55 & & & & \\
\hline Van & 5 & 12.2 & & & & \\
\hline \multicolumn{7}{|l|}{ Belt use in private vehicles? } \\
\hline Always use & 183 & 26.79 & -0.4671 & 0.417233086 & 0.0644671 & -7.24556 \\
\hline Don't always use & 86 & 73.5 & & & & \\
\hline \multicolumn{7}{|c|}{ Are CMVs safer than private vehicles? } \\
\hline Yes & 138 & 39.05 & 0 & 0.3905 & 0.0867746 & 0 \\
\hline No & 41 & 39.05 & & & & \\
\hline \multicolumn{7}{|l|}{ Stops per hour } \\
\hline Less than 1 per hour & 7 & 26.92 & -0.686 & 0.340190476 & 0.205492 & -3.33833 \\
\hline $1-2$ stops per hour & 48 & 27.43 & & & & \\
\hline $3-4$ & 58 & 29.59 & & & & \\
\hline $5+$ & 139 & 38.5 & & & & \\
\hline \multicolumn{7}{|l|}{ Seat belt law apply to CMVs? } \\
\hline Yes & 170 & 26.36 & -0.5599 & 0.342777778 & 0.0968036 & -5.78388 \\
\hline No & 28 & 82.35 & & & & \\
\hline \multicolumn{7}{|l|}{ How much encouragement? } \\
\hline None & 73 & 46.5 & -0.5334 & 0.37112179 & 0.1247177 & -4.27686 \\
\hline Periodic & 87 & 36.1 & & & & \\
\hline $1-2$ times & 45 & 44.55 & & & & \\
\hline Constant encouragement & 52 & 19.19 & & & & \\
\hline \multicolumn{7}{|c|}{ Years driving CMV? $($ mean = 13.9) } \\
\hline Above the mean & 125 & 35.82 & 0.0389 & 0.337376208 & 0.0578004 & 0.673006 \\
\hline Below the mean & 144 & 31.93 & & & & \\
\hline \multicolumn{7}{|c|}{ Miles driven per week in CMV? $($ mean $=517.25)$} \\
\hline Above the mean & 61 & 38.61 & 0.0621 & 0.338082156 & 0.0688799 & 0.901569 \\
\hline Below the mean & 208 & 32.4 & & & & \\
\hline \multicolumn{7}{|c|}{ Number of accidents in CMV? $($ mean $=0.79)$} \\
\hline Above the mean & 102 & 38.78 & 0.0768 & 0.34012119 & 0.0595342 & 1.290014 \\
\hline Below the mean & 167 & 31.1 & & & & \\
\hline
\end{tabular}

had a policy requiring seat belt use when driving on the job (Block, 1998). And if workers believed that their company had a seat belt policy, they also tended to believe that it was enforced at least to some degree (Block, 1998).

In the Hawaii study, when asked what would encourage CMV drivers to "buckle up?" the responses were quite mixed. Only $38 \%$ felt that more education would help encourage belt use, with $62 \%$ believing that it would not. While $46 \%$ believed that more police enforcement would encourage belt use, $54 \%$ believed that it would not. Approximately $61 \%$ believed that company policy would encourage belt use, while $39 \%$ believed that it would not. Amazingly, $95 \%$ of the respondents checked that "nothing" would serve to encourage more belt use among CMV drivers.
When asked, "how much encouragement do you receive from your company or supervisor to "buckle up" $20 \%$ responded "none," $13 \%$ responded "mentioned once or twice," $31 \%$ indicated "periodic reminders" and $35 \%$ said that they received "constant encouragement."

According to a NHTSA study done in 1998.

When asked "does the mandatory belt use law apply to CMV drivers," only $85 \%$ of the respondents replied "yes." Four percent said "no" and $11 \%$ stated that they "did not know." In asking what the fine for not wearing a seat belt, only 8 out of 572 professional drivers who responded to this question, gave the correct answer (\$92). The most common response (162 responses) was $\$ 75$, followed by $\$ 77$ (122 responses). 
Table 3

Logistic regression of always using a seatbelt vs. not always using a seatbelt

\begin{tabular}{|c|c|c|c|c|c|c|c|c|}
\hline & d.f. & Estimate & S.E. & Wald $\chi^{2}$ & Prob. value & Odds ratios & \multicolumn{2}{|c|}{ 95\% Wald confidence limits } \\
\hline Intercept & 1 & -1.316 & 0.5072 & 6.7336 & 0.0095 & & & \\
\hline Others (always belted $=1$; not always belted $=0$ ) & 1 & 2.2853 & 0.3146 & 52.7605 & $<0.0001$ & 9.829 & 5.305 & 18.210 \\
\hline Police $($ yes $=1 ;$ no $=0)$ & 1 & 0.5605 & 0.1886 & 8.8324 & 0.0030 & 1.752 & 1.210 & 2.535 \\
\hline Nothing $($ yes $=1 ;$ no $=0)$ & 1 & -1.2498 & 0.4349 & 8.2597 & 0.0041 & 0.287 & 0.122 & 0.672 \\
\hline Personal vehicle (always belted $=1$; not always belted $=0$ ) & 1 & 1.8032 & 0.2547 & 50.1094 & $<0.0001$ & 6.069 & 3.684 & 9.998 \\
\hline SB law apply $($ yes $=1$; other $=0)$ & 1 & 1.6952 & 0.2573 & 43.4055 & $<0.0001$ & 5.448 & 3.290 & 9.021 \\
\hline Gender $($ male $=1 ;$ female $=0)$ & 1 & -0.927 & 0.4195 & 4.8841 & 0.0271 & 0.396 & 0.174 & 0.900 \\
\hline Accident (in accident $=1 ;$ no accident $=0$ ) & 1 & -0.5233 & 0.1956 & 7.158 & 0.0075 & 0.593 & 0.404 & 0.869 \\
\hline CMV type $($ truck $=1 ;$ other $=0)$ & 1 & -0.7235 & 0.2065 & 12.2718 & 0.0005 & 0.485 & 0.324 & 0.727 \\
\hline Percent concordant & & 83.1 & & & & & & \\
\hline Percent discordant & & 13.8 & & & & & & \\
\hline Percent tied & & 3.1 & & & & & & \\
\hline Pairs & 1428 & 339 & & & & & & \\
\hline Somer's $D$ & & 0.693 & & & & & & \\
\hline Gamma & & 0.715 & & & & & & \\
\hline Tau- $a$ & & 0.31 & & & & & & \\
\hline$c$ & & 0.846 & & & & & & \\
\hline
\end{tabular}

\subsection{Differences between users and non-users}

Tables 1 and 2 serves to highlight the differences between those who say they "always" use seat belts in their CMVs and those who don't. Some interesting results emerge. Females $(87.7 \%)$ are much more likely than males $(64.6 \%)$ to report "always" using seat belts when operating a CMV. Older drivers, those above the mean age are also more likely $(72.7 \%)$ to "always" use belts compared to those with ages below the mean $(60.5 \%)$. Yet interestingly, those who are above the mean in terms of years driving are slightly less likely to report "always" using seat belts in their CMVs compared to those below the mean in years driving $(68.1 \%)$. Truck drivers $(58.8 \%)$ have the lowest proportion of those who "always" use belts compared to bus $(86.5 \%)$ and van $(87.8 \%)$ operators. Approximately $73.2 \%$ of those who "always" use belts in their personal vehicles also "always" use them in their CMVs. There is no statistically significant difference between those who believe CMVs are safer than their personal vehicles in terms of reporting "always" using belts in their CMVs. There is, however, a statistical significant relationship between the non-use of belts and the frequency of stops. Note that only $61.5 \%$ of those who make five or more stops per hour report that they use seat belts "always" compared to $73 \%$ of those who make less than one stop per hour. Approximately $74 \%$ of those who believe that the seat belt law applies to CMV drivers use seat belts "always." Notably, those who receive "constant encouragement" from their supervisors have the highest proportion of "always" use seat belts in their CMV (80.8\%) compared to only $53.5 \%$ of those who don't receive encouragement to buckle up. Those who are above the mean in terms of miles driven per week are less likely to report using their belts always $(61.4 \%)$, than those below the mean $(67.6 \%)$. Finally, those who report having more accidents than the mean level are less likely to "always" use belts $(61.2 \%)$ compared to those had fewer accidents than the mean number $(68.9 \%)$.

\subsection{Modeling self-reported seat belt use}

In order to better understand the relationships between selfreported belt use and various driver, vehicle, and other factors, a logistic regression model was constructed. The dependent variable was expressed as the probability of reporting "always" using seat belts, run against all of the various variables in the dataset. Using "backwards elimination" the overall effects of each variable was tested in order to produce the best-fitting most robust model. In addition, various subsets of the model were operationalized and tested, including a trucks only model and a van/bus combination model. The results showed, overall, a similar pattern in terms of predicting self-reported seat belt use amongst CMV drivers.

The results of the best performing model are presented in Table 3. The parameter estimates show the size and direction of the effect. Only statistically significant results have been included. All are statistically significant at the 0.05 level and most are also significant at the 0.001 level as well. The variable "others" corresponds to question 2, asking respondents if other CMV drivers use their seat belts. "Police" corresponds to question 4, and refers to whether or not they believe that "enforcement would encourage use." The variable "Nothing" also corresponds to question 4 , and is based on the response that "nothing would help encourage belt use." The "personal vehicle" term is based on question 6 , and refers to those who claim to "always" use belts in their personal vehicle. "SB Law" variable refers to question 15, and pertains to whether respondents believe the "seat belt law applies to CMV drivers." The "Gender" variable corresponds to question 21 , and refers to being male as opposed to female. The "accident" variable is based on question 11, and pertains to whether or not the CMV driver reported having an accident in the CMV. "CMV type" is truck versus bus/vans/other vehicle types and is based on question 17 . The odds ratios provide a convenient way of interpreting the results. 
Based on the column of odds ratios, it is apparent that there are some strong effects. For example, those who believe that other CMV drivers "always" wear their seat belts are 9.8 times more likely to also report "always" using their belts than those who don't believe that others "always" wear their belts. Similarly, those who report "always" using their belts in their personal vehicles are more than 6 times as likely as those who don't always use their belts in their personal vehicle to buckle up in their CMVs. Another strong effect (odds ratio of 5.5) was found for those who believe that the seat belt law applies to CMV drivers. They are more than five times more likely to report always using their belts than those who don't believe the law applies to CMV drivers. Those who believe that "nothing will encourage seat belt use" are much less likely (odds ratio $=0.287$ ) than those who believe in strategies for encouraging belt use. Truck drivers (odd ratio $=0.45$ ) and males (odds ratio $=0.396$ ) are much less likely to report "always" in terms of seat belt use than either bus/van operators or female drivers. One of the most interesting findings of the survey is that those who report being involved in accidents are much less likely to report "always" using seat belts when driving a CMV. This seems to support the notion that those who are more careful, take less risks and have less accidents, and are also the most likely to be belt users.

\section{Discussion}

This study contributes to the ongoing investigations of compliance with mandatory restraint use laws both in Hawaii (Kim and Tremblay, 2005) and elsewhere (Knoblauch et al., 2003). It reinforces some of the earlier findings both regarding the observed use of seat belts and possible motivations for non-compliance with the law. This study supplements the observational studies which have found a lower use rate among CMV drivers than other motorists. This is somewhat surprising given the fact that professional drivers receive additional training and given their added exposure to the hazards of road, one would think that they would have higher use rates than other motorists.

A review and discussion of the findings in this light sheds additional light on the topic. While $67 \%$ of the respondents said that they (themselves) "always use seat belts when driving a CMV?" Only $31 \%$ of them believed that "other CMV drivers" use seat belts "always." The fact that CMV drivers believe that the use rate of other drivers is less than half their own use rate is telling. This finding does support the general observation that even among CMV drivers there is recognition that seat belt use is less than it should be.

Even if you combine together those who state that they "always" (67\%) and "usually" (14\%) wear their seat belts in their CMVs, the use rate $(81 \%)$ is still far below the observed use rate for motorists (over 95\%). The survey supports the contention that seat belt use rates by CMV drivers are lower than other motorists.

The attitudinal survey supports the observational studies in a number of ways. The observed use rate for vans and buses was much higher than that of trucks. Females were also observed to have a higher use rate than males. But the attitudinal survey enabled collection of more detailed background information than could be gathered through observational surveys. Older drivers were more likely to report that they "always" use a seat belt. Naturally, we found a high correlation between those who used seat belts and those who believed that others used seat belts while operating CMVs. We also found that those who used seat belts in their personal vehicles were also more likely than those who did not to use belts while driving a CMV. Those who correctly understood that the seat belt law applies to CMV operators were also more likely to report "always" using their belts. Moreover those who believed that "police enforcement" encourages belt use and who received many reminders from their company or supervisor were also more likely to be in the "always use" category. But those who make frequent stops are less likely to be in the group of using seat belts "always."

The attitudinal survey suggests that there may be need for improved seat belt design or perhaps re-engineering of seat belt technology. Approximately $12 \%$ of the respondents stated discomfort as a reason for non-use of seat belts. Another $6 \%$ stated "no/faulty" seat belts as a reason for non-use. Twentynine percent of the respondents stated that frequent stops and inconvenience associated with buckling up are reasons for nonuse. These concerns, taken together, suggest a need for improved harness design, perhaps better ergonomics or other engineering solutions to make it easier for CMV operators to put on or take off their seat belts. This may be particularly important for those who make frequent stops who also report having the lowest levels of compliance.

The survey also suggests that there may be need for more enforcement of seat belt laws among CMV operators. While only $46 \%$ of the respondents believed that more enforcement would encourage greater compliance, it is also interesting to note that $14 \%$ believed that there is "more enforcement" of the seat belt law for personal vehicles than for CMVs.

While enforcement may be an important component of an overall program to increase compliance, it would appear that educational programs may be more important. There were sizeable numbers who either didn't realize that the belt law applies to CMV operators or weren't aware of the fines for non compliance. Notably, those who received "constant encouragement" from their company or supervisors to "buckle up" were the most likely to be in the "always use" category. Indeed, one of the major reasons given for non-use as well as for the seemingly contradictory behavior of using belts in their personal vehicles but not in their CMVs is not being "safety conscious." Promotion of safety, therefore, might serve to encourage greater understanding of the benefits of belt use in terms of injury reduction and also lead to increased use of belts among CMV drivers.

The logit model results suggest a multi-tiered approach to increasing belt use in Hawaii. In addition to educating more drivers about the law and perhaps using enforcement or the threat of enforcement, it would also appear that there are communal values associated with increased compliance. The fact demonstrated by the model that those who believe that others "always" use their belts are also many time more likely to claim that they too "always" use belts when operating CMVs suggests that perceived behavior of others might influence belt use. Education programs, company reminders, and publicly disseminated 
information that CMV drivers are changing their behavior may serve to create an incentive for some non-users to begin using their seat belts. Perhaps increased belt use will beget more use.

\section{Conclusions}

In this section, following a discussion of the limitations and caveats of the study, some policy recommendations and future directions for additional research are described.

\subsection{Limitations and caveats}

There are, no doubt, as with any study, some limitations and caveats. The first applies to the location of the study. While Hawaii is part of the United States, it is different from other states in terms of the absence of long-distances and interstate long-haul trucking operations. The attitudes and self-reported behaviors, therefore, may not apply to truckers and other commercial vehicle operators who may travel much longer distances. While there are rural, urban, industrial, and commercial areas, and mix of highway, arterial, and local streets, there are some differences between this state and others on the mainland. Those same factors which provide excellent controls on the study such as its isolation and insular status, might also be used to argue that the results here are somewhat exceptional. Perhaps one way to address this issue is to conduct some comparative research-using the questions and result from Hawaii as a basis for developing a research agenda in another state. For this reason, the complete questionnaire has been included in Appendix 1.

Another potential compounding factor is that the survey was distributed by the Motor Carrier Safety staff. While this ensured a very high response rate, one might be concerned that it also influenced the nature of the responses. The instrument stressed that the responses were to remain "confidential and anonymous." Also, questions were asked in several different ways to solicit responses regarding belt use. Respondents were asked about their own use as well the use of others. A combination of both check-off responses and open-ended questions were included. A point of this study was also to raise attention to these issues. By distributing 1000 questionnaires on seat belt use to CMV drivers throughout the state, there may also be positive, educational benefit resulting from asking drivers about belt use. Notably this is part of a larger project that involves conducting regular observational studies and also, potentially, enforcement and educational campaigns.

Finally, there is the potential problem referred to in the literature as the "lie factor." Respondents to questionnaire may be less than truthful. This has been noted in our previous research (Kim, 1999), and has been well described in the literature as the "consistency controversy (Liska, 1975). This problem can confound traffic safety research because there are incentives to lie. CMV drivers might fear fines, although the police, not the Motor Carrier Safety staff are responsible for enforcement of the seat belt law or they might feel compelled to report that they use belts when they don't. There are two different instances of potentially lying. First and more common is the case that CMV drivers say that they use belts, but actually don't. They, are, in fact, exaggerating their belt use. And this would appear to be the case, given the fact that the observed use rate is so much lower than the actual use rate. We can estimate these differences by comparing the observed use rate which we have previously estimated to be between 58.8 and $72.7 \%$ to the self-reported rate, $67 \%$ claim to "always" use belts. These values are not terribly different. The other group of potential liars is much more problematic. Of course there are those who actually use belts, but then for reasons of misguided bravado or other unknown reasons, claim to be non-users. In the attitudinal survey, $11 \%$ of the respondents claimed to "rarely" or "never" use belts. Given the fact that the observed use rate is so much lower than this amount, it is safe to assume that virtually all of those claiming not to use belts, indeed, are non-users.

The best way to use the survey is in conjunction with other databases. The observational information provides part of the picture. Crash data also reveals insight into use and non-use of belts. The attitudinal data, with the limitations and caveats as described, also helps to understand the dynamics of belt use among CMV drivers.

\subsection{Implications for policy}

This study suggests three different directions for enhancing seat belt use among CMV drivers. First, there is a need to better understand the motivations and concerns and inconveniences of belt use by drivers who make frequent stops. Getting in and out of the vehicle, having to make maneuvers related to stopping, starting, parking, and perhaps loading and unloading CMVs may be associated with seat belt non-use. Perhaps there are vehicle, seat, harness, and other technological changes which could be made to promote seat belt use. Or not. Second, there is also a need to better study the motivational aspects of enforcement. Are the fines perceived to be insignificant? Is there a belief that police do not or will not enforce the law? Does the increased visibility of being in a large CMV lead drivers to believe that they will see police before the police will see them? Finally, there is need of more educational and public information strategies for boosting belt use among CMV operators. The survey and the logit model demonstrated that public education and encouragement from employers and supervisors are positively associated with increased self-reported belt use. There are also communal values associated with seat belt use, as users are more likely to believe that others also use belts.

\subsection{Further research}

This study has highlighted the need for more research on the motivations and behaviors of CMV drivers who have had more training than other motorists yet don't use seat belts as often.

Perhaps more detailed interviews and focus group meetings with non-users would be helpful in better understanding the rationale for not buckling up. One way to explore these topics further would be present this research to a panel of CMV drivers to determine if there are other explanations or factors contributing to non-use of safety restraints. It would also be interesting 
to look more closely at the relationship between driving records and seat belt use. The indication here is that those who have had a higher frequency of crashes are less likely to be belt users. Perhaps belt use might be proxy for other safe practices in operating CMVs. More research is needed to determine, definitely, that belt using CMV drivers are, indeed, safer than non-users.

In addition to more comparative research, with other states there is need for more research on variable seat belt use. It would be interesting to study and compare the characteristics of those who report "always" using seat belts to those who may use belts only part of the time. Understanding the motivations of 'part-time' belt users may give additional insight into how to better increase compliance. Particularly as use rates continue to increase, it may be important to study the temporal, environmental, and circumstantial factors associated with differential belt use. This is particularly interesting given that so many of the respondents (though not all of them) reported using belts "always" in their personal vehicles. Finally, there is need to conduct more research on the "communal values" associated with not just seat belt use but also promoting a culture of safety.

\section{Acknowledgements}

The authors would like to acknowledge the support of Larry Oshiro and the Hawaii Department of Transportation and Wendy Cunningham of the Federal Motor Vehicle Carrier Safety Office, U.S. Department of Transportation.

\section{Appendix A. Commercial motor vehicle (CMV) operator survey}

Please answer the following questions. Do not place any identifying information on this survey. This survey is anonymous and confidential. Please choose the answers that best describe you.

1. How often do you use seat belts when driving a CMV? [791, 100\%]

\begin{tabular}{|c|c|c|}
\hline Always & {$[531,67 \%]$} & $\square$ Rarely [66, 8\%] \\
\hline Usually & {$[114,14 \%]$} & $\square$ Never $[27,3 \%]$ \\
\hline About half the time & {$[53,7 \%]$} & \\
\hline
\end{tabular}

2. To your knowledge, how often do other CMV drivers use seat belts? [774, 100\%]

\begin{tabular}{|c|c|c|}
\hline Always & {$[238,31 \%]$} & $\square$ Rarely $[121,16 \%$ \\
\hline Usually & {$[255,33 \%]$} & $\square$ Never $[17,2 \%]$ \\
\hline About half the time & {$[143,18 \%]$} & \\
\hline
\end{tabular}

3. What are reasons why CMV drivers do not use seat belts? [677, 100\%]

\begin{tabular}{|c|c|}
\hline Not Safety Conscious & {$[153,23 \%]$} \\
\hline Feel Safe in big vehicle & {$[36,5 \%]$} \\
\hline Discomfort & {$[84,12 \%]$} \\
\hline No/Faulty Seatbelt & {$[40,6 \%]$} \\
\hline \multicolumn{2}{|c|}{ Frequent Stops/inconvenience[198, 29\%] } \\
\hline Don't know/not sure & {$[78,12 \%]$} \\
\hline Other & {$[88,13 \%]$} \\
\hline
\end{tabular}

4. What of the following would encourage CMV drivers to buckle up?

$\square$ More education [Yes:299,38\%, NO:493,62\%] $\square$ More reminders [Y:301,38\%,N:491,62\%]

$\square$ Police enforcement[Y:365,46\%,N:426,54\%] $\square$ Company policy[Y:483,61\%,N:309,39\%]

$\square$ Nothing $\quad[\mathrm{Y}: 754,95 \%, \mathrm{~N}: 38,5 \%] \quad \square$ Other $\quad[\mathrm{Y}: 74,9 \%$,
$\mathrm{N}: 718,91 \%]$

5. How much encouragement do you receive from your company or supervisor to buckle up?[770, 100\%]
$\square$ None $[157,20 \%]$
Mentioned once or twice [101,13\%]
$\square$ Periodic reminders[241,31\%]
Constant encouragement [271,35\%]

6. How often do you use seat belts when you drive a personal vehicle? [791, 100\%]
Always
$[683,86 \%]$
$\square$ Rarely [16,2\%]
Usually
[63,8\%]
About half the time
$[19,2 \%]$
$\square$ Never $[10,1 \%]$ 
7. Why do you think some CMV drivers do not buckle up in their CMVs but do use seat belts in their personal vehicle?

Not Safety Conscious [648,100\%]

Feel Safe in big vehicle $[78,12 \%]$

Discomfort $[97,15 \%]$ [40,6\%]

No/Faulty Seatbelt $[29,4 \%]$

Frequent Stops/inconvenience[89,14\%]

Lack of enforcement at work $[9,1 \%]$

Family

More Police enforcement in POV $\quad[90,14 \%]$

Don't know/not sure

Other

$[105,16 \%]$

8. Do you feel safer on the road in a CMV than in your personal vehicle? [792,100\%]
$\square$ Yes
$[386,49 \%]$
$\square$ No
[105,13\%]
Does not make a difference
[301,38\%]

9. If you answered "Yes" to Question \#8, please briefly explain why? [332,100\%]

Larger vehicle [223,67\%]

Visibility $\quad[40,12 \%]$

Educated $\quad[3,1 \%]$

Cautious Driving $\quad[19,6 \%]$

Other [47,14\%]

10. How long have you been driving a CMV?
$0<$ years $<=1$ : $\quad[37,5 \%]$
$1<$ years $<=5: \quad[150,20 \%]$
$5<$ years $<=10: \quad[147,20 \%]$
$10<$ years $<=15 \quad[124,17 \%]$
$15<$ years $<=20 \quad[121,16 \%]$
$20<$ years $<=25 \quad[65,9 \%]$
$25<$ years $<=30 \quad[58,8 \%]$
$30<$ years $<=35 \quad[24,3 \%]$
$35<$ years $<=40 \quad[11,1 \%]$
$40<$ years $\quad[5,<1 \%]$

11. How many accidents have you been involved in as a CMV driver? accidents $(740,100 \%)$

$\begin{array}{ll}0 & {[477,64 \%]} \\ 1 & {[142,19 \%]} \\ 2 & {[65,9 \%]} \\ 3 & {[34,5 \%]} \\ 4 & {[10,1 \%]} \\ 5 & {[5,<1 \%]} \\ 6-9 & {[4,<1 \%]} \\ 10+ & {[3,<1 \%]}\end{array}$

12. On average, how many miles do you drive in your CMV each week? miles per week $[699,100 \%]$

0 miles:

$[9,1 \%]$

1-10: $\quad[20,3 \%]$

11-50: $\quad[59,8 \%]$

51-100: $\quad[107,15 \%]$

101-200: $\quad[96,14 \%]$

201-300: [64,9\%]

301-400: $\quad[60,9 \%]$

401-500: $\quad[126,18 \%]$

501-1000: $\quad[113,16 \%]$

1001+: $\quad[45,6 \%]$ 
13. For your job, approximately how many stops (where you actually get out of your CMV) do you usually make per hour as a CMV driver? [758,100\%]
$\square 0$ times
[26,3\%]
$\square 3$ to 4 times
$[196,25 \%]$
$\square \quad 1$ to 2 times
$[175,23 \%]$
$\square 5$ or more times
$[361,48 \%]$

14. During which of these times are you more likely to wear a seat-belt in your CMV?

$[705,100 \%]$
$\square \quad 7 \mathrm{am}-11 \mathrm{am}[65,9 \%]$
$3 \mathrm{pm}-7 \mathrm{pm}[8,1 \%]$
$11 \mathrm{am}-3 \mathrm{pm}[24,3 \%]$
$\square 7 \mathrm{pm}-7 \mathrm{am} \quad[29,4 \%]$
$\square \quad$ Time of day does not make a difference $[579,82 \%]$

15. To your knowledge, does Hawaii's mandatory seat belt law apply to CMV drivers?

$[759,100 \%]$
$\square$ No
$[34,4 \%]$
$\square$ Yes $[645,85 \%]$
$\square$ Do not know
$[80,11 \%]$

16. In Hawaii, what is the fine for not wearing a seatbelt? $\$$

See attached e-mail for distribution

17. What type of CMV do you drive the most? [755,100\%]
Truck
$\square$ Bus
$[155,21 \%]$
$\square$ Van $[41,5 \%]$
$\square$ Other $\quad[51,7 \%]$

18. What year (model) is this CMV?

19. What type of seat belt is in this vehicle? [744,100\%]

$\square$ Lap/shoulder belt combination [514,69.1\%]

$\square$ Lap belt only $\quad[229,30.77 \%]$

None

$[1,0.13 \%]$

20 . What is the company or agency you work for?

21 . What is your gender? $[767,100 \%]$

$\square$ Female $[73,10 \%]$

$\square$ Male $[694,90 \%]$

22. What is your age?

$<21$ Years: $[2,<1 \%]$

21-29: $\quad[104,14 \%]$

30-39: $\quad[186,25 \%]$

40-49: $\quad[254,34 \%]$

50-59: $\quad[153,20 \%]$

60-69: $\quad[48,6 \%]$

70+: $\quad[7,1 \%]$

Thank you for participating in this survey. This survey is anonymous and confidential.

\section{References}

Agresti, A., 1990. Categorical Data Analysis. John Wiley and Sons.

Block, A.W., 1998. The 1998 Motor Vehicle Occupant Safety Survey. vol. 2: Seat Belt Report. Publication DOT HS 809 051. National Highway Traffic Safety Administration.

Feinberg, S., 1980. The Analysis of Cross-Classified Categorical Data. MIT Press, Cambridge.

FMCSA, 2005. Safety Belt Myths and Facts. Federal Motor Carrier Safety Administration. http://www.fmcsa.dot.gov/safetybelt/Seatbelt_Myths1.htm (accessed July 21, 2005)

Kim, K., Tremblay, D.M., 2005. Presented at 84th Annual Meeting of the Transportation Research Board, Washington, DC. The observed use of restraints by large vehicle operators in Hawaii.

Kim, K., Yamashita, E., 2001. Asleep at the wheel: spatial and temporal patterns of fatigue-related crashes in Honolulu. In: Transportation Research Record: Journal of the Transportation Research Board, No. 1779, TRB. National Research Council, Washington, DC, pp. 46-53.

Kim, K., 1999. The lie factor in traffic safety: comparison of police and hospital reporting of seat belt and alcohol use in Hawaii. In: Transportation Research Record: Journal of the Transportation Research Board, No. 1665, TRB. National Research Council, Washington, DC, pp. 141-146.

Kim, K., Li, L., 1996. Modeling fault among bicyclists and drivers involved in collisions in Hawaii. In: Transportation Research Record: Journal of the Transportation Research Board, No. 1538, TRB. National Research Council, Washington, DC, pp. 75-80.

Knoblauch, R., et al., 2003. Safety Belt Usage By Commercial Motor Vehicle Drivers. Publication DTMC-01-P-00071. Federal Motor Carrier Safety Administration.

Liska, A., 1975. The Consistency Controversy. Readings on the Impact of Attitudes on Behavior. John Wiley and Sons, New York. 